\title{
Políticas educacionais inclusivas no Brasil: o caso da rede municipal de ensino de Santo André
}

\author{
Celso do Prado Ferraz de Carvalho ${ }^{1}$ \\ Amanda Sousa Batista do Nascimento ${ }^{2}$
}

\begin{abstract}
Resumo
Este artigo apresenta resultados de pesquisa realizada na Rede Municipal de Santo André-SP, cujo objetivo foi analisar o processo de implementação da Política Nacional de Educação Especial na Perspectiva da Educação Inclusiva. Por meio da fala das professoras e assistentes pedagógicos mapeou práticas e obstáculos ocorridos na implementação da política. Os procedimentos metodológicos consistiram na revisão de literatura acerca da implementação de políticas educacionais inclusivas, na análise de documentos tanto nacionais como estrangeiros sobre o tema e em um conjunto de entrevistas semiestruturadas realizadas com professores e assistentes pedagógicos de duas Unidades Escolares. O contexto mais amplo da pesquisa foi fundamentado na abordagem do ciclo de políticas, formulado por Ball, e as entrevistas na análise de discurso, de Orlandi. A pesquisa demonstrou como o processo de implementação de política pública envolve aspectos institucionais, demarcados pela legislação vigente, e aspectos individuais, definidos pela autonomia do professor.
\end{abstract}

Palavras-chave: Política Nacional de Educação Especial na Perspectiva da Educação Inclusiva. Profesi sores. Alunos com deficiência.

\begin{abstract}
This article presents research results from the Municipal Network of Santo André-SP, whose objective was to analyze the implementation process of the National Policy on Special Education in the perspective of Inclusive Education. Through the speech of teachers and pedagogical assistants, it mapped out practices and obstacles that occurred in the implementation of the policy. The methodological procedures consisted of a review of the literature on the implementation of inclusive educational policies, the analysis of both national and foreign documents on the subject and a set of semi-structured interviews with teachers and pedagogical assistants from two School Units. The broader context of the research was grounded in Ball's policy-cycle approach and interviews in Orlandi's discourse analysis. The research demonstrated how the process of implementation of public policy involves institutional aspects, demarcated by the current legislation, and individual aspects, defined by the autonomy of the teacher.
\end{abstract}

Keywords: Educational Policies. National Policy on Special Education in the Perspective of Inclusive Education. Teachers. Students with disabilities.

\footnotetext{
${ }^{1}$ Doutor em Educação. Professor do Programa de Pós Graduação em Educação - Departamento de Educação - Universidade Nove de Julho. E-mail: cpfcarvalho@gmail.com

${ }^{2}$ Mestre em Educação; Professora efetiva da Secretaria Municipal de Educação de Santo André (SP). E-mail: amandasousabatista1987@gmail. com
} 


\section{Introdução}

O tema Educação Inclusiva, objeto desse artigo, tem sido amplamente discutido pela área da Educação, sendo objeto de tensões, polêmicas e certos consensos. Com a Política Nacional de Educação Especial na Perspectiva da Educação Inclusiva de 2008, que visa garantir o acesso e permanência dos educandos com defíciência na escola regular, a existência de vagas nas escolas públicas passou a ser direito das famílias.

Essa política suscitou intensos debates, entre eles, acerca das condições em que os alunos são inseridos na sala de aula, sobre as condições de trabalho oferecidas aos professores e demais profissionais da educação que trabalham especificamente no processo de inclusão destes alunos, bem como sobre o posicionamento dos gestores municipais para sua implantação e implementação.

A relevância acadêmica e social da Educação Inclusiva é imensa, em razão da quantidade de crianças com deficiência nas escolas regulares e a necessidade de a elas garantir oportunidades para desenvolver autonomia e identidade, sua condição de cidadão e a inserção no mercado de trabalho. Nesse processo, analisar a implantação da Política Nacional de Educação Inclusiva pode revelar aspectos importantes, especificamente os avanços que possibilita, e as dificuldades que enfrenta.

Nesse artigo apresentamos resultado de pesquisa que teve o objetivo de problematizar a implementação da Política Nacional de Educação Especial na Perspectiva da Educação Inclusiva na Rede Municipal de Ensino de Santo André. Para tanto, realizamos um duplo movimento metodológico: o primeiro consistiu na análise de documentos e da legislação sobre Educação Inclusiva, nacional e internacional e a leitura e sistematização a revisão da literatura sobre a Política Nacional de Educação Especial na Perspectiva da Educação Inclusiva; o segundo implicou na realização de entrevistas com gestores, professores e assistentes pedagógicas de duas escolas da rede municipal, definidas pelo fato de trabalharem sob a égide da Política Nacional de Educação Especial na Perspectiva da Educação Inclusiva, sendo que uma delas Polo Bilíngue de Educação de Surdos e Deficientes Auditivos.

O texto inicialmente apresenta o percurso metodológico que orientou a pesquisa, na sequencia problematiza o conceito de inclusão, relata a experiência histórica da Rede Municipal de Santo André com as políticas de inclusão e, por fim, a análise das entrevistas feitas com professores e assistentes pedagógicas.

\section{0 percurso metodológico}

O contexto amplo da pesquisa foi fundamentado na abordagem do ciclo de políticas (BALL, MAINARDES, 2011; VIDOVICH, 2002; MAINARDES, 2006). Para Mainardes (2006), essa abordagem se constitui em importante procedimento de análise da trajetória de processos micropolíticos e da ação dos profissionais que lidam com as políticas no nível local, caracterizando estes processos como ciclos contínuos, com três faces: a política proposta, a política de fato e a política em uso. A política proposta diz respeito às intenções dos governantes, departamentos educacionais e burocratas com a função de implementar políticas, bem como as intenções no lócus destas políticas, isto é, nas escolas. A política de fato se refere ao marco regulatório oficial, aos textos políticos e legislativos que direcionam as ações-base para a efetivação da referida política. Já as políticas em uso são os discursos e práticas desenvolvidas a partir do processo de implementação das políticas pelos gestores educacionais. 
Para as entrevistas, utilizamos a Análise do Discurso (AD). De acordo com Orlandi (2009) a AD procura compreender a língua enquanto sentido, enquanto trabalho simbólico, parte do trabalho social geral, constitutivo do homem e da sua história. AAD considera os processos e as condições de produção da linguagem pela análise da relação estabelecida pela língua com os sujeitos que falam e as situações em que se produz o dizer.

A Análise do Discurso não estaciona na interpretação, trabalha seus limites, seus mecanismos, como parte dos processos de significação. Também não procura um sentido verdadeiro através de uma "chave" de interpretação. Não há esta chave, há método, há construção de um dispositivo teórico. Não há uma verdade oculta atrás do texto. Há gestos de interpretação que o constituem e que o analista, com seu dispositivo, deve ser capaz de compreender (ORLANDI, 2009, p. 26).

Neste texto temos dois grupos discursivos: os locutores, representados pela Secretaria Municipal de Educação de Santo André, sob a égide da Política Nacional de Educação Especial na Perspectiva da Educação Inclusiva, e os interlocutores, os professores e assistentes pedagógicos de duas unidades escolares da referida rede. Por conseguinte, o conjunto de transcrições das entrevistas coletadas foi analisado e convertido em objetos teóricos, agrupando trechos/frases compreendidas como gestos de interpretação.

As entrevistas foram realizadas em Unidades Escolares, chamadas pela nomenclatura de Escola Municipal de Educação Infantil e Ensino Fundamental (E.M.E.I.E.F.). A escolha da EMEIEF Nicolau Moraes de Barros, localizada no centro da cidade, ocorreu em razão de possuir projeto de Polo Bilíngue de Educação de Surdos e Deficientes Auditivos, concomitantemente ao atendimento dos demais alunos com outras deficiências e estudantes sem deficiência. A EMEIEF Cândido Portinari, que fica na periferia da cidade, foi escolhida em razão do fato de receber grande número de estudantes com deficiência, com grande distância entre a residência dos alunos e a escola, o que implica também em pensar as condições de acesso e permanência destes alunos.

Os sujeitos entrevistados são professores concursados da Rede Municipal de Santo André, com idade entre 26 e 57 anos, cujo tempo de magistério varia bastante, entre 5 anos de atuação e 30 anos de efetivo exercício. Entre as entrevistadas, 8 trabalham como professoras de sala de aula regular e 3 ocupam cargos de função gratificada, como Assistentes Pedagógicas das escolas locus desta pesquisa. As professoras possuem formação em nível superior, bem como cursos de especialização. O roteiro de entrevistas destinado às professoras e assistentes pedagógicas foi estruturado a partir de grandes eixos: Política de Educação Inclusiva, Formação do Professor, Assessoria Especializada, Trabalho Pedagógico, Infraestrutura e Acessibilidade e Relação com as famílias dos alunos com deficiência.

\section{Políticas públicas inclusivas no Brasil}

No Brasil, os registros históricos nos mostram que as primeiras formas de atendimento das pessoas com deficiência iniciaram-se na época imperial, com a criação de instituições específicas para atendimento de pessoas cegas e surdas: o Imperial Instituto dos Meninos Cegos, em 1854 e o Instituto dos Surdos Mudos, em 1857. Hoje, estas instituições possuem outras denominações: Instituto Benjamin Constant - IBC e Instituto Nacional da Educação dos Surdos - INES, ambos localizados no Rio de Janeiro. Por conseguinte, já no século XX, são fundadas 
outras instituições, em 1926 o Instituto Pestalozzi para atendimento de pessoas com Deficiência Mental, hoje denominada como Deficiência Intelectual, de acordo com o DSM-V³; em 1954 surge a primeira Associação de Pais e Amigos dos Excepcionais e em 1945, surge o primeiro Atendimento Educacional Especializado (A.E.E.) às pessoas com superdotação, oferecido por Helena Antipoff, na Sociedade Pestalozzi.

Marco importante no recente debate acerca do direito das pessoas com deficiência à educação é o documento que resulta da Conferência Mundial de Educação para Todos, de 1990 (UNESCO, UNICEF, PNUD, BM). Poucos anos depois temos a Declaração de Salamanca, de 1994, marco histórico para a educação de pessoas com deficiência, ao defender que mesmo pessoas com deficiências severas tenham direito a educação. São documentos com significativo impacto no debate educacional brasileiro e que foram importantes no debate e na definição das políticas de inclusão.

A Política Nacional de Educação Especial na Perspectiva da Educação Inclusiva, elaborada pelo governo federal em 2008, estabelece princípios e caminhos que podem servir de referência para governos estaduais e municipais. Não se constitui em política de Estado, mas sim de uma proposição do governo, o que significa que sua incorporação fica a critério dos demais governos. Visa orientar programas e ações nessa área e promover o acesso e a permanência de alunos com deficiência, transtornos globais do desenvolvimento e altas habilidades/ superdotação, público alvo da Educação Especial, especificamente no ensino regular. Almeja ampliar a oferta do atendimento educacional especializado e romper com o modelo até então existente, estruturado nas escolas a partir das denominadas classes especiais.

O texto base da Política Nacional de Educação Especial na Perspectiva da Educação Inclusiva reafirma que o paradigma da educação inclusiva é um movimento mundial, de cunho político, cultural, social e pedagógico, fundamentado no direito de todo indivíduo com deficiência de ingressar na escola, de estar junto aos demais, com oportunidades equiparadas de aprender, participar, sem sofrer nenhum tipo de discriminação. O referido paradigma está pareado com a concepção dos direitos humanos, em que a igualdade e a diferença são valores que caminham juntos (BRASIL, 2008).

Defende a garantia do direito à educação aos educandos com deficiência e almeja contemplar todos aqueles que possuem deficiências de ordem física, intelectual, auditiva (surdos, surdos-cegos, visual, múltipla deficiência e transtorno do espectro autista), bem como assegurar direitos aos alunos com transtornos funcionais específicos, relacionados a dificuldades específicas de aprendizagem, ligadas a alterações no Sistema Nervoso Central, como por exemplo, o Transtorno de Déficit de Atenção e Hiperatividade (TDAH), a dislexia, disgrafia, discalculia, entre outros.

É uma política pública educacional, que perpassa e transita pelo campo de políticas públicas inclusivas, ou políticas de ação afirmativa. Os defensores das políticas públicas de ação afirmativa para a sociedade afirmam que seus objetivos não podem estar associados somente a medidas circunstanciais, de emergência, ou demandas latentes da população. Defendem que elas devem ter caráter de universalização de direitos sociais e políticos, e agir no sentido de contribuir com a diminuição das desigualdades.

Para Aranha (1995), negar aos deficientes a possibilidade de integração social, implica em dupla perda, individual e coletiva. Perde o indivíduo ao ter seus direitos negados e perde a sociedade por não ter a oportunidade e a possibilidade de aprender com significativa parcela de seus cidadãos. Ainda segundo Aranha (2001), a oferta de oportunidades equiparadas não é sinônimo de normalização, isto é, tentar tornar as pessoas com deficiência o mais

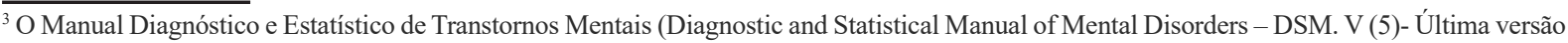
publicada em 2013. 
próximo das pessoas ditas normais. O processo de desqualificação é diretamente ligado ao sistema capitalista, que considera o deficiente um peso, que não produz e não contribui com o aumento do capital. Para o autor:

Não adianta prover igualdade de oportunidades, se a sociedade não garantir o acesso da pessoa com deficiência a essas oportunidades. Muitos são os suportes necessários e possíveis de imediato. Outros demandam maior planejamento a médio e longo prazo, caso se pretenda alcançar uma sociedade justa e democrática (ARANHA, 2001, p .21).

Martins (1997) alerta para a necessidade de que o debate sobre inclusão e suas políticas incorpore uma discussão ampla, que considere o processo social, suas contradições, especificamente a forma como as pessoas se localizam, particularmente no mundo do trabalho e na vida social em geral. Para ele:

[...] exclusão de fato, sociologicamente, não existe. Ela é na sociedade moderna, apenas um momento da dinâmica de um processo mais amplo, um momento insuficiente para compreender e explicar todos os problemas que a exclusão efetivamente produz na sociedade atual (MARTINS, 1997, p. 26).

A Política Nacional de Educação Especial na Perspectiva da Educação Inclusiva é um projeto que visa discutir, elaborar, planejar, implementar e avaliar um projeto educativo específico para as pessoas com deficiência, mas sem negar a esses educandos as mesmas condições e oportunidades equiparadas de acesso, que os demais alunos têm.

\section{A experiência na rede municipal de Santo André}

Santo André, em 1989, primeiro mandato do prefeito Celso Daniel, diante dos efeitos do desemprego e baixo crescimento econômico, já discutia ações e projetos para o exercício da cidadania, para a educação, inclusão social, desenvolvimento econômico e participação popular.

A Rede Municipal de Ensino de Santo André possui, desde 1989, experiência na organização e planejamento educacional no atendimento aos alunos com deficiência. É importante destacar, que tendendo às demandas de descentralização do poder trazidas pela Constituição de 1988, os municípios passaram a ter autonomia e discricionariedade na forma de administrar a educação em conformidade com o cenário das políticas educacionais naquele período. Desta maneira, "apontando para a descentralização do poder, a Constituição de 1988 coloca dispositivos que indicam conferir total autonomia político-administrativa aos municípios, declarando os mesmos como esferas autônomas entre as outras que compõem a federação.” (BATISTÃO, 2013, p. 63).

No artigo 247 da Lei Orgânica do Município de Santo André, há a indicação de que os gestores municipais irão organizar:

[...] o sistema municipal de ensino, providenciando o atendimento escolar nas modalidades de: 
I. Educação Infantil.

II. Educação de Jovens e Adultos.

III. Educação Especial (SANTO ANDRÉ, 1990, p.1)

A Rede Municipal de Ensino de Santo André possui uma política inclusiva que não se limita aos aspectos educacionais, mas à inclusão social na cidade. De acordo com o Histórico da Educação Inclusiva - Balanço Social ${ }^{4}$ (SANTO ANDRÉ, 2007) desenvolvido pelo Instituto Paradigma, enquanto a média nacional de inclusão de crianças com deficiência na escola pública era de $0,6 \%$, em relação ao total de matrículas, em Santo André ela chegou a 2,8\% no início de 2007, quase quatro vezes mais. São atendidas 798 estudantes com deficiência, num universo de 28.549 crianças. Este atendimento não se limita a crianças, uma vez que o município também atende jovens e adultos com deficiência.

Batistão (2013) esclarece que em Santo André, a inclusão educacional é uma realidade desde a década de 1990, mas ficou com os contornos mais definidos a partir de 1999/2000. Nesse momento, ocorre a implantação do Centro de Atenção ao Desenvolvimento Educacional (CADE), uma agência do governo municipal, que responde ao departamento da Secretaria Municipal de Educação responsável por "avaliar os alunos com deficiência, promover a sua inclusão nas escolas, acompanhar o seu desenvolvimento e possibilitar a capacitação profissional dos educadores que atuam nessa área, dando-lhes o suporte necessário” (p. 70).

A lei Orgânica do município, em seu artigo segundo, determina as competências do CADE:

Auxiliar o professor no diagnóstico das dificuldades relativas ao ensino e aprendizagem apresentadas, prioritariamente, aos alunos com necessidades educativas especiais; orientar os professores do ensino regular de educação infantil, ensino fundamental, educação de jovens e adultos e os monitores de creche que interagem com alunos com necessidades especiais; propor caminhos para a superação das dificuldades encontradas, de ordem pedagógica ou clínica, nas instâncias adequadas, oferecer atendimento clínico em parceria com a Secretaria de Saúde; estender o atendimento especializado aos demais usuários e formar os funcionários da unidade (SANTO ANDRÉ, 2000, p.1).

O CADE faz parte do Programa de Educação Inclusiva e teve origem em 1998, quando o município fez a opção de ter uma Rede própria de Ensino Fundamental, no contexto das mudanças na legislação, em razão da criação do Fundo de Manutenção e Desenvolvimento do Ensino Fundamental e de Valorização do Magistério (FUNDEF). Santo André tinha apenas uma rede de Educação Infantil e, posteriormente, Educação de Jovens e Adultos e Ensino Profissionalizante. Foi feita a opção de trabalhar com a primeira infância (até 10 anos) e depois com a Educação de Jovens e Adultos e Ensino Profissionalizante. O município não trabalha com as séries do Ensino Fundamental II na modalidade Regular (somente com a modalidade EJA II) e nem com o Ensino Médio, cabendo esta responsabilidade de oferta de atendimento na cidade ao governo do Estado de São Paulo.

\footnotetext{
4 Publicação da Secretaria de Educação de Santo André em parceria com o Instituto Paradigma, um parceiro da prefeitura durante o período de 2000-2008. A publicação traz a história do atendimento de alunos com deficiência na Secretaria de Educação e Formação Profissional (SEFP), com o título: A educação inclusiva no município de Santo André (SP).
} 
A segunda parte de nosso estudo consistiu na realização de entrevistas semiestruturadas, que foram realizadas durante o período de outubro a dezembro/2017, com assistentes pedagógicos e professores em efetivo exercício na Rede Municipal de Santo André. O roteiro foi construído a partir dos objetivos que foram estabelecidos pela política nacional, de modo que fosse possível mapear e analisar o processo de implementação no âmbito municipal. Apresentamos a seguir os dados obtidos e a análise realizada.

\section{Os resultados obtidos: as categorias utilizadas e a análise das entrevistas com professores}

A análise do conteúdo coletado nas entrevistas utilizou como instrumentos os conceitos da Análise de Discurso (AD) que, de acordo com Orlandi (2009), procura compreender a língua enquanto sentido, enquanto trabalho simbólico, parte do trabalho social geral, constitutivo do homem e da sua história.

Os dados mostram semelhanças e discrepâncias na forma que professores que atuam na EMEIEF Nicolau Morais de Barros e na EMEIEF Cândido Portinari compreendem a categoria Política de Educação Inclusiva. No discurso das professoras da EMEIEF Nicolau Morais de Barros, identificamos uma trajetória formativa favorável à inclusão de estudantes com deficiência na sala regular. Isto se reforça com o fato de que o pólo bilíngue é considerado um espaço plenamente adequado para atender estes educandos.

No discurso das professoras da EMEIEF Cândido Portinari, há o reconhecimento de todos os esforços dos gestores municipais na implementação da Política Nacional de Educação Especial na Perspectiva da Educação Inclusiva, contudo, há uma série de fatores elencados que justificam que a rede ainda está aquém do esperado. Entre os fatores elencados por estas professoras, como a qualidade do ensino oportunizado aos estudantes com deficiência, foi evidenciada a existência da lei municipal nº.233/2001, intitulada Lei Dinah Zecker, que assegura a matrícula imediata de alunos com deficiência nas unidades escolares mais próximas de sua residência, independentemente de vaga. Esta lei causou um impacto relevante em regiões com número maior de estudantes com deficiência, visto que, apesar de garantir o acesso aos educandos com deficiência, também aumentou consideravelmente o número de estudantes por sala nas diferentes modalidades de ensino. Esta medida foi considerada como algo que paulatinamente desqualifica o ensino oferecido e se enquadra em um modelo de inclusão excludente, como afirma Padilha (2009). Na análise da categoria Formação do Professor, os dados mostram que, mesmo com constantes esforços e ações desenvolvidas pela rede municipal de Santo André para a formação continuada dos professores sobre a temática da Educação Inclusiva, a falta de formações específicas sobre cada tipo de deficiência e suas comorbidades é realçada. Esse discurso ocorreu em todas as entrevistas com professoras, que também mencionaram fatores que prejudicam a participação dos professores como: oferta de formação fora do horário de trabalho, incompatibilidade de temas atrelados às necessidades cotidianas, às diferentes modalidades de ensino, principalmente no caso da EJA, a falta de informação sobre as formações, entre outros. Nos discursos analisados é intensa a percepção da discrepância existente entre as propostas dos documentos oficiais e a realidade vivenciada nas escolas, além do sentimento de despreparo que os professores sentem mediante os desafios de incluir a todos.

No que diz respeito à categoria Assessoria Especializada (CADE), todas as professoras entrevistadas tiveram discursos similares em relação ao trabalho desenvolvido pelas PAEI's. Foi evidenciado que essas profissionais não atuam de maneira uniforme nas diferentes Unidades Escolares e esse fator influencia nos resultados a serem 
obtidos no decorrer do processo de ensino e aprendizagem de estudantes com deficiência. Além disso, as entrevistadas concordam que o número de PAEI's que atuam na rede é insuficiente, mediante a quantidade de escolas para atender, com situação agravada nas Unidades Escolares maiores, cujo número de estudantes com deficiência é maior. Um aspecto positivo apresentado no discurso das entrevistadas é que, apesar de algumas falhas na atuação destas profissionais, elas são muito importantes na efetivação da Política Nacional de Educação Especial na Perspectiva da Educação Inclusiva.

A categoria Trabalho Pedagógico demonstrou insatisfação no discurso de algumas entrevistadas, principalmente no que concerne à Política idealizada pelo documento oficial e a Política de fato implementada, pois esta discrepância é visualizada diretamente no trabalho pedagógico desenvolvido, classificado como falho, justificado pela falta de formação específica para os professores. É preciso destacar nesta categoria que as falhas no trabalho pedagógico inclusivo apareceram com maior frequência no discurso das professoras da EMEIEF Cândido Portinari, enquanto no discurso das entrevistadas da EMEIEF Nicolau Morais de Barros é possível identificar a vantagem em ter nesta Unidade Escolar o funcionamento de um pólo bilíngue de educação de surdos e deficientes auditivos, com maior suporte.

$\mathrm{Na}$ análise da categoria infraestrutura e acessibilidade, foi evidenciado que os benefícios da implementação do pólo bilíngue em 2016 na EMEIEF Nicolau Morais de Barros, bem como a atuação do CAEM em parceria concomitante com o trabalho desenvolvido na sala de aula regular, trouxe resultados significativos para o processo de ensino e aprendizagem dos estudantes com deficiência matriculados na rede municipal de ensino. A proximidade deste equipamento da EMEIEF Nicolau Morais de Barros foi classificada pelas entrevistadas como uma vantagem na qualificação do trabalho pedagógico desenvolvido. No discurso das professoras que atuam na EMEIEF Cândido Portinari, surgiu a necessidade de repensar os espaços escolares para melhor atender estes estudantes, garantir a manutenção dos mesmos bem como a adaptação de materiais, implementação de novas salas de recursos multifuncionais, assessoria mais próxima das PAEI's (para professores e estagiários de apoio à inclusão).

Os dados analisados referentes à categoria Relação com as famílias dos estudantes com deficiência, no caso das entrevistadas que atuam na EMEIEF Nicolau Morais de Barros, apontam para a importância da parceria com os profissionais do CAEM com a equipe gestora da Unidade Escolar, com ações que aproximam as famílias da escola em prol da inclusão efetiva dos educandos. Em relação ao discurso das professoras da EMEIEF Cândido Portinari, foi possível notar a falha neste aspecto, na aproximação entre escola e famílias dos estudantes com deficiência.

No caso das análises das entrevistas com as Assistentes Pedagógicas, sendo duas da EMEIEF Nicolau Morais de Barros e uma da EMEIEF Cândido Portinari, os principais dados levantados foram o pioneirismo da rede municipal de Santo André na implementação de políticas educacionais inclusivas em relação a outras redes de ensino, com ênfase na falta de continuidade educativa quando os alunos com deficiência tentam prosseguir seus estudos na rede estadual de ensino, por exemplo.

As assistentes pedagógicas destacaram o aspecto positivo de que a Gerência de Educação Inclusiva, não é composta por profissionais contratados a parte, mas sim, por professores da rede, o que demonstra proximidade com os anseios dos demais professores da rede. $\mathrm{O}$ histórico do $\mathrm{CADE}$ em oferecer diferentes tipos de formações para equipes gestoras e professores, surgiu nos discursos como ação efetiva para garantir a implementação da política inclusiva.

Os dados mostram como aspectos negativos a resistência de alguns professores acerca da educação inclusiva, devido à falta de preparo e de respaldo por parte da Secretaria de Educação na linha de frente do processo de 
implementação da referida política, isto é, a realidade vivenciada nas Unidades Escolares. Por conseguinte, há o reconhecimento de que, entre as mudanças político-partidárias nas gestões municipais, existem modificações nos encaminhamentos das políticas inclusivas, embora alguns aspectos mais estruturais sejam reaproveitados.

O discurso destas profissionais trouxe o reconhecimento da necessidade de maior investimento na formação específica para os professores acerca da Política Nacional de Educação Especial na Perspectiva da Educação Inclusiva. No caso específico da modalidade de ensino da Educação de Jovens e Adultos, surgiu o fator essencial da garantia de maior respaldo e acompanhamento por parte do CADE, elucidando que o formato no qual há PAEI específica para o setor de EJA foi um ganho qualitativo na opinião da entrevistada.

\section{Considerações finais}

Frente a estas análises e problematizações, fazemos aqui as seguintes considerações: a política educacional inclusiva vem sendo implementada nesta rede de ensino antes mesmo da redação oficial deste documento de 2008, o vanguardismo da rede municipal de Santo André na formulação e implantação de uma nova agenda de gestão pública ocorre desde 1989, por meio de lei orgânica que previa a oferta de educação a estudantes com deficiência.

Com o passar dos anos, as políticas educacionais inclusivas em âmbito municipal foram se fortalecendo, com o respaldo legal de documentos nacionais e internacionais. O ápice ocorre com a adesão à Política Nacional de Educação Especial na Perspectiva da Educação Inclusiva (2008) que fortaleceu o CADE como órgão responsável pela implementação desta política. Destaque deve ser conferido à Lei Dinah Zecker de 2001, cujo objetivo foi ampliar o acesso e a permanência dos educandos com deficiência nas escolas regulares municipais. Além disso as entrevistas revelam muitas outras conquistas, como a criação do CAEM, do Polo Bilíngue de Educação de Surdos e Deficientes Auditivos, a contratação de estagiárias de apoio à inclusão, a implantação de Salas de Recursos Multifuncionais e a oferta de formação continuada aos professores da rede, acerca das temáticas inerentes à Educação Inclusiva.

\section{Referências}

ARANHA, M. S. F. Integração social do deficiente: análise conceitual e metodológica. Temas em Psicologia, Universidade Estadual Paulista, Bauru, n. 2, p. 63-70, 1995.

Paradigmas da relação da sociedade com a pessoa com deficiência. Revista do Ministério Público do Trabalho, Ano XI, n. 21, p.1-24, março 2001.

BALL, S.; J. MAINARDES, J. (org.). Política educacional e análises de políticas: questões e dilemas. São Paulo: Cortez, 2011.

BATISTÃO, S. P. da S. Educação Inclusiva ou Educação para todos? Contribuições da teoria histórico-cultural para uma análise crítica da realidade escolar. Dissertação (Mestrado). Universidade de São Paulo, Programa de Pós-Graduação em Mudança Social e Participação Política, 2013.

BRASIL. Ministério da Educação. Secretaria de Educação Especial. Política Nacional deEducação Especial na Perspectiva da Educação Inclusiva. Brasília: MEC/SEESP. 
MAINARDES, J. Abordagem do ciclo de políticas. Uma contribuição para a análise de políticas educacionais.

Educação e Sociedade, v. 27, n. 94, 47-69, 2006. Disponível em http://www.scielo.br/pdf/es/v27n94/a03v27n94.pdf

MARTINS, J. de S. Exclusão social e a nova desigualdade. São Paulo: Paulus, 1997.

ORLANDI, E. P. Análise de Discurso: princípios \& procedimentos. 8. ed. Campinas: Pontes, 2009.

PREFEITURA DO MUNICÍPIO DE SANTO ANDRÉ. Secretaria de Educação. Disponível em: http://www2.santoandre.sp.gov.br/index.php/2013-03-20-17-29-08/2013-03-20-17-30-14/institucional-sedu>, Acesso em: jul. 2015.

UNESCO. Declaração de Salamanca e linha de ação sobre necessidades educativas especiais. Brasília: CORDE, 1994.

UNESCO. Declaração Mundial sobre Educação para Todos. Plano de ação para satisfazer as necessidades básicas de aprendizagem. Jomtien, Tailândia, 1990.

VIDOVICH, L. Expanding the toolbox for policy analysis: some conceptual and practical approaches. Hong Kong: Comparative Education Policy Research Unit, University of Hong Kong, 2002. 